\title{
Effect of Laser Shock Peening on the Surface Morphology of Metallic Glasses
}

\author{
Yansen $\mathrm{Li}^{1, \mathrm{a}}$, Kun Zhang ${ }^{1, \mathrm{~b}}$, Guihua Duan ${ }^{2, \mathrm{c}}$, Guangyue $X \mathrm{u}^{3, \mathrm{~d}}$, Yuhang Wei ${ }^{1, \mathrm{e}}$, \\ Yanpeng $\mathrm{Wei}^{4, \mathrm{f}}$ and Bingchen Wei ${ }^{1, \mathrm{~g}, *}$
}

${ }^{1}$ Key Laboratory of Microgravity (National Microgravity Laboratory), Institute of Mechanics, Chinese Academy of Sciences, Beijing 100190, China

${ }^{2}$ State Key Laboratory of Nonlinear Mechanics, Institute of Mechanics, Chinese Academy of Sciences, Beijing 100080, China

${ }^{3}$ China Electronics Technology Group Corporation No.38 Research Institute, Hefei 230031, China

${ }^{4}$ Key Laboratory for Mechanics in Fluid-Solid Coupling Systems, Institute of Mechanics, Chinese Academy of Sciences, Beijing 100190

aliyansen@imech.ac.cn, bzhangku@imech.ac.cn, 'duanguihua@imech.ac.cn, d163xgybuaab@163.com, e'wyh_112062122@163.com, fweiyanpeng@imech.ac.cn, geibc@imech.ac.cn

Keywords: Laser Shock Peening, Metallic Glass, Surface Morphology

\begin{abstract}
Laser shock peening is a promising effective approach for improving mechanical properties of metallic glass. In this work, laser shock peening was employed to study the surface morphologies of metallic glasses with different toughness. Numerous localized circular- or arc-shaped structures, with the size of 5 20 $\mu \mathrm{m}$, were observed in the shock treated surface. The number of these unique localized structures has a close correlation to the ability of metallic glass to accommodate plastic deformation. In addition, the surface morphology evolution of Zr-based metallic glasses with different crystalline degrees is also discussed, indicating that the circular- or arc-shaped structures only appear in fully amorphous system.
\end{abstract}

\section{Introduction}

Bulk metallic glasses (BMGs), which possess many attractive properties including high strength, elastic deformability and corrosion resistance, have great application potentials as structural materials. However, with a low macroscopic plasticity, their applications are impeded by catastrophic brittle fracture at room temperature [1]. Many researchers have adopted a variety of surface treatment methods to improve their plasticity. For example, laser melting is utilized to induce tensile residual stress to improve the mechanical properties [5]. Shot peening is also taken to improve their plasticity by introducing compressive residual stress into the sample surface [7]. Laser shock peening (LSP) is a sort of novel surface treatment technology developed in recent years [9]. Compared with conventional shot peening, the intensity is more steady and steerable. However, there have been relatively few studies on the manner in which laser shock peening acts on BMGs, the effects of LSP in different systems of BMGs remain unclear.

In this paper, numerous localized circular- or arc-shaped structures, dozens of micrometers in length, are observed. The responses of above mentioned localized structures in different systems and crystalline degrees are discussed.

\section{Experimental Procedures}

$\mathrm{La}_{63.1} \mathrm{Al}_{15.2}(\mathrm{Cu}, \mathrm{Ni})_{21.7}, \mathrm{Zr}_{47.9} \mathrm{Ti}_{0.3} \mathrm{Ni}_{3.1} \mathrm{Cu}_{39.3} \mathrm{Al}_{9.4}$ and $\mathrm{Ti}_{40} \mathrm{Zr}_{25} \mathrm{Be}_{30} \mathrm{Cr}_{5}$ BMGs were prepared by arc melting a mixture of elements, respectively. These ingots were remelted and chill casted into a $5 \mathrm{~mm}$ cylindrical copper mold in a Ti-gettered argon atmosphere. The BMG rods were cut to $2 \mathrm{~mm}$-thick sections, then ground and polished under a standard metallographical procedure to a mirror finish. The alloy structure before and after LSP was characterized by X-ray diffraction (XRD) using $\mathrm{Cu} \mathrm{K} \alpha$ 
radiation. Thermal analyses of the specimens were performed in differential scanning calorimeter (Netzsch DSC 404C) at a heating rate of $20 \mathrm{~K} / \mathrm{min}$ under argon atmosphere. Crystallization was obtained by isothermal annealing treatments.

LSP was performed with a Q-switched high power Nd: YAG pulse laser operating at $1064 \mathrm{~nm}$ wavelength. A maximum of $2.5 \mathrm{~J}$ output energy per shot was achieved through a two-step amplification system. The full width at half maximum was approximately $7.32 \mathrm{~ns}$. The laser beam size was about $2 \mathrm{~mm}$ in diameter with the laser intensity larger than $7 \mathrm{GW} \mathrm{cm}-2$. An aluminum foil was glued on the target surface as an absorption layer, confined by a $4.00 \mathrm{~mm}$ thick $\mathrm{K} 9$ glass against the laser irradiation. The aluminum foil $(\sim 40 \mu \mathrm{m})$ was chosen to ensure that only the upper part of the foil was melted and ionized by the laser energy. The scanning electron microscopy (SEM) and the atomic force microscope (AFM) were used to depict the detailed surface morphology of the impacted area after LSP.

\section{Results and Discussion}
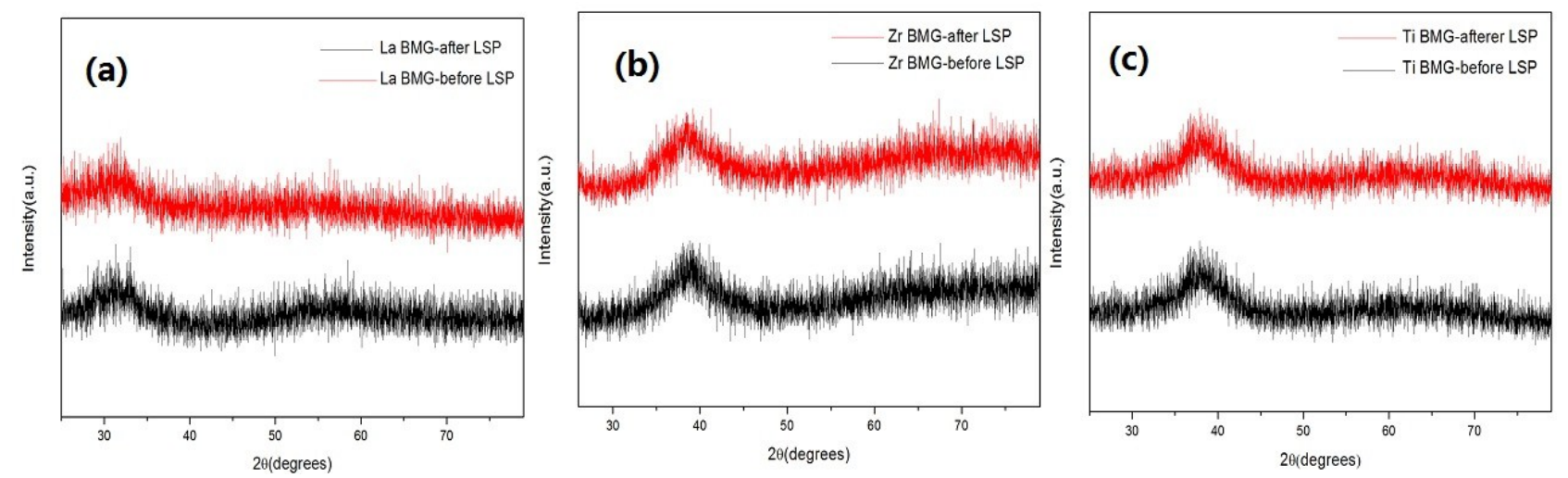

Fig. 1 XRD patterns of (a) La-based, (b) Zr-based and (c) Ti-based BMGs

Fig. 1 shows the XRD patterns of $\mathrm{La}_{63.1} \mathrm{Al}_{15.2}(\mathrm{Cu}, \mathrm{Ni})_{21.7}, \mathrm{Zr}_{47.9} \mathrm{Ti}_{0.3} \mathrm{Ni}_{3.1} \mathrm{Cu}_{39.3} \mathrm{Al}_{9.4}$ and $\mathrm{Ti}_{40} \mathrm{Zr}_{25} \mathrm{Be}_{30} \mathrm{Cr}_{5}$ BMGs. Three types of BMG alloys show broad diffraction peaks before LSP, which confirm that all the alloys are amorphous. After LSP, sharp Bragg peak doesn't appear in any above mentioned XRD results. This means that LSP treatment could not result into crystallization in amorphous structure.

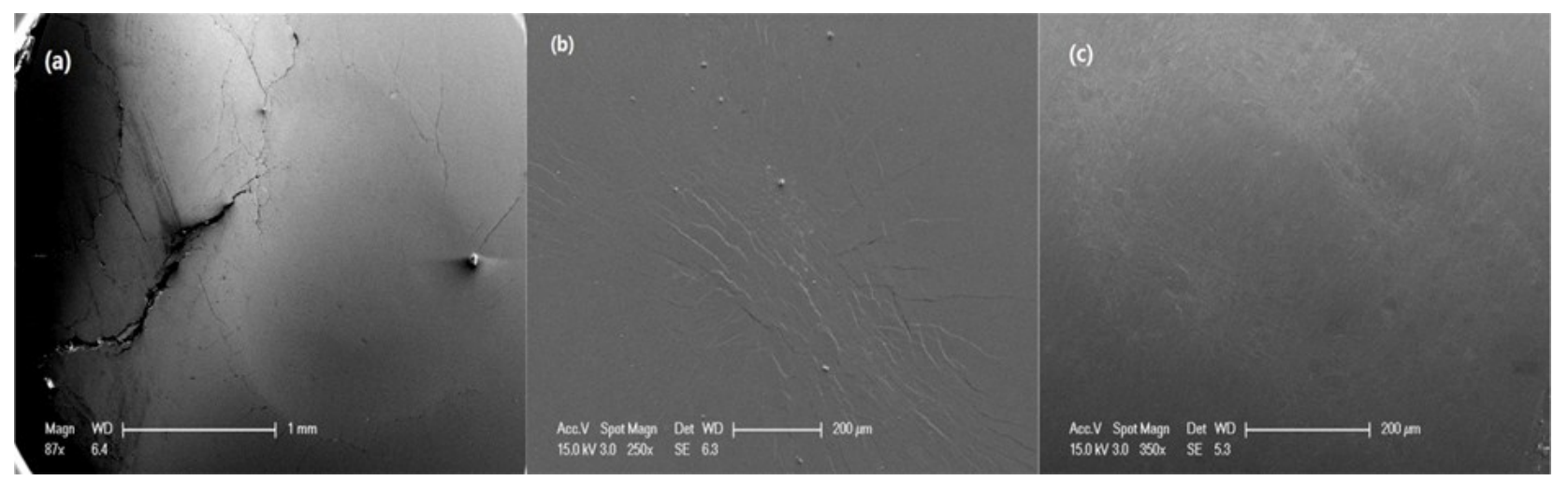

Fig. 2 Macroscopical SEM images of (a) La-based, (b) Zr-based and (c) Ti-based BMGs after LSP

The surface morphologies in different BMGs are characterized by SEM. As shown in Fig. 2 (a), a typical brittle fracture can be observed on the surface of La-based BMG, which indicates that the material has undergone catastrophic plastic deformation. The depth of the dent is about $35 \mu \mathrm{m}$, measured by the surface contourgraph. Around the impacted crater, obvious cracks are observed along the edge. However, a slight dent can be found with the depth of $15 \mu \mathrm{m}$ as shown in Fig. 2 (b). And, there is no distinct deformation in Ti-based BMGs as shown in Fig. 2 (c). 


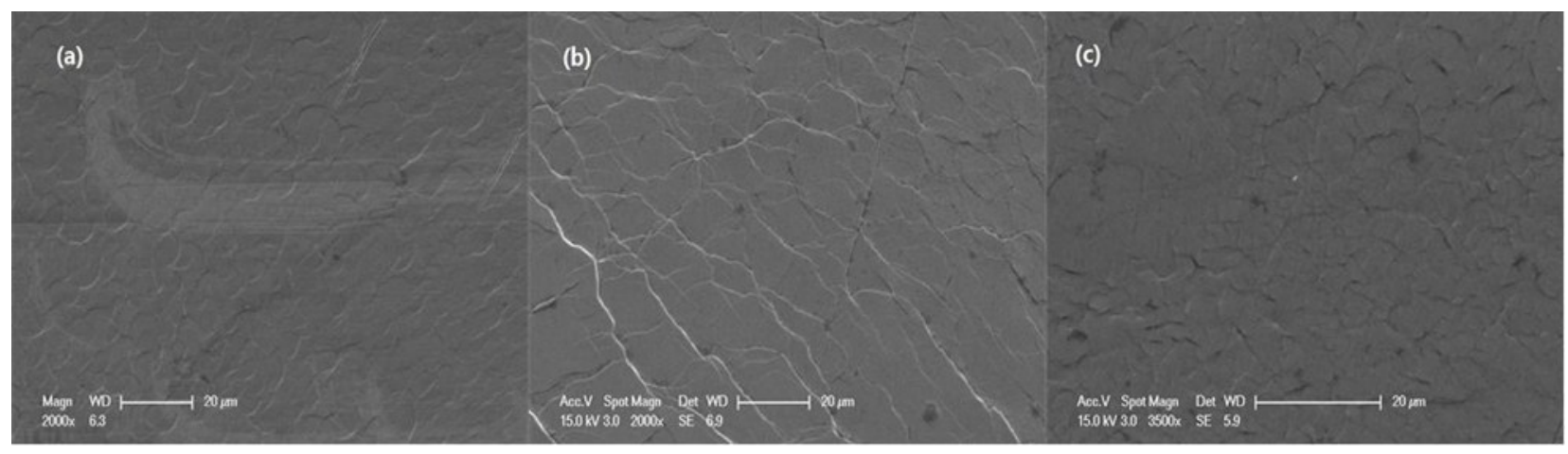

Fig. 3 Microcosmic SEM images (a) La-based, (b) Zr-based and (c) Ti-based BMGs

For further research the surface morphology of above mentioned BMGs, the microcosmic SEM images were obtained in Fig. 3. It is noted that numerous localized circular- or arc-shaped structures, with the size of 5 20 $\mu \mathrm{m}$, are observed in the impacted crater. As shown in Fig. 3 (a), the number of circle-shaped structures is larger than the one of arc-shaped structures in the center of the crater of La-based BMG. However, the arc-shaped structures are dominating in $\mathrm{Zr}$ and Ti-based BMGs (in Fig. 3 (b) and (c)). Moreover, arc-shaped structures tend to overlap in Ti-based BMGs, which exhibit more complicated distributions. Up to now, there are rarely reports about this kind of structure on the surface of BMGs.

The yield strength and limited plastic strain of BMGs can reflect the toughness [13]. The relationships between the surface feature and toughness of BMGs are supplied in Table 1. Ti-based and La-based BMGs exhibit the highest and lowest toughness respectively among three types of BMGs. The number densities of feature structures show a positive correlation with the toughness of BMGs. In contrast, the dimensions of local structures are negatively related to toughness of BMGs. From table 1, we can conclude that in the higher toughness of BMGs, the distribution of circle- and arc-shaped structures in the impacted area would be more intense, and their size is smaller.

Table 1 Plastic parameters and surface features in different BMGs systems [17]

\begin{tabular}{|c|c|c|c|c|}
\hline Specimen & $\begin{array}{c}\text { Yield } \\
\text { strength } \\
(\mathrm{GPa})\end{array}$ & $\begin{array}{c}\text { Limited } \\
\text { plastic strain } \\
(\%)\end{array}$ & $\begin{array}{c}\text { Dimension of } \\
\text { local structures } \\
(\mu \mathrm{m})\end{array}$ & $\begin{array}{c}\text { Number } \\
\text { Density } \\
\left(/ \mathrm{mm}^{2}\right)\end{array}$ \\
\hline $\begin{array}{c}\text { La-based } \\
\text { BMG }\end{array}$ & 0.65 & 1.28 & $5 \sim 20$ & 25556 \\
\hline $\begin{array}{c}\text { Zr-based } \\
\text { BMG }\end{array}$ & 1.5 & 3.51 & $5 \sim 15$ & 36875 \\
\hline $\begin{array}{c}\text { Ti-based } \\
\text { BMG }\end{array}$ & 1.72 & 5.36 & $3 \sim 12$ & 48125 \\
\hline
\end{tabular}

For materials with low toughness, damage will occur if the pressure it suffered is higher than Hugoniot elastic limit (HEL) [19]. A metal's HEL is related to the dynamic yield strength according to Johnson and Rhode [20]. In our experiment, a laser shock peening with an absorbent coating and confining medium, an un-axial compressive stress is generated along the direction of the shock wave. As the shock wave propagates into the BMGs, plastic deformation occurs to a depth at which the peak pressure exceeds BMGs' HEL. Due to the nominal plasticity of La-based BMG, cracks arise on the surface.

At present, most investigations have concentrated on the deformation behavior under the condition of quasi static and low speed dynamic load. The highest strain rate upon BMGs in their research is generally lower than $10^{4} \mathrm{~s}^{-1}$. However, during LSP, the compressive pressure appears in the form of shock wave with the strain rate excessing to $10^{6} \mathrm{~s}^{-1}$. In addition, the action time of LSP on the sample lasts only $35 \mathrm{~ns}$ with impact strength up to $8.2 \mathrm{GPa}$. These extreme conditions may play a key role in the formation of circle- and arc- shaped structures on the surface of BMGs. 


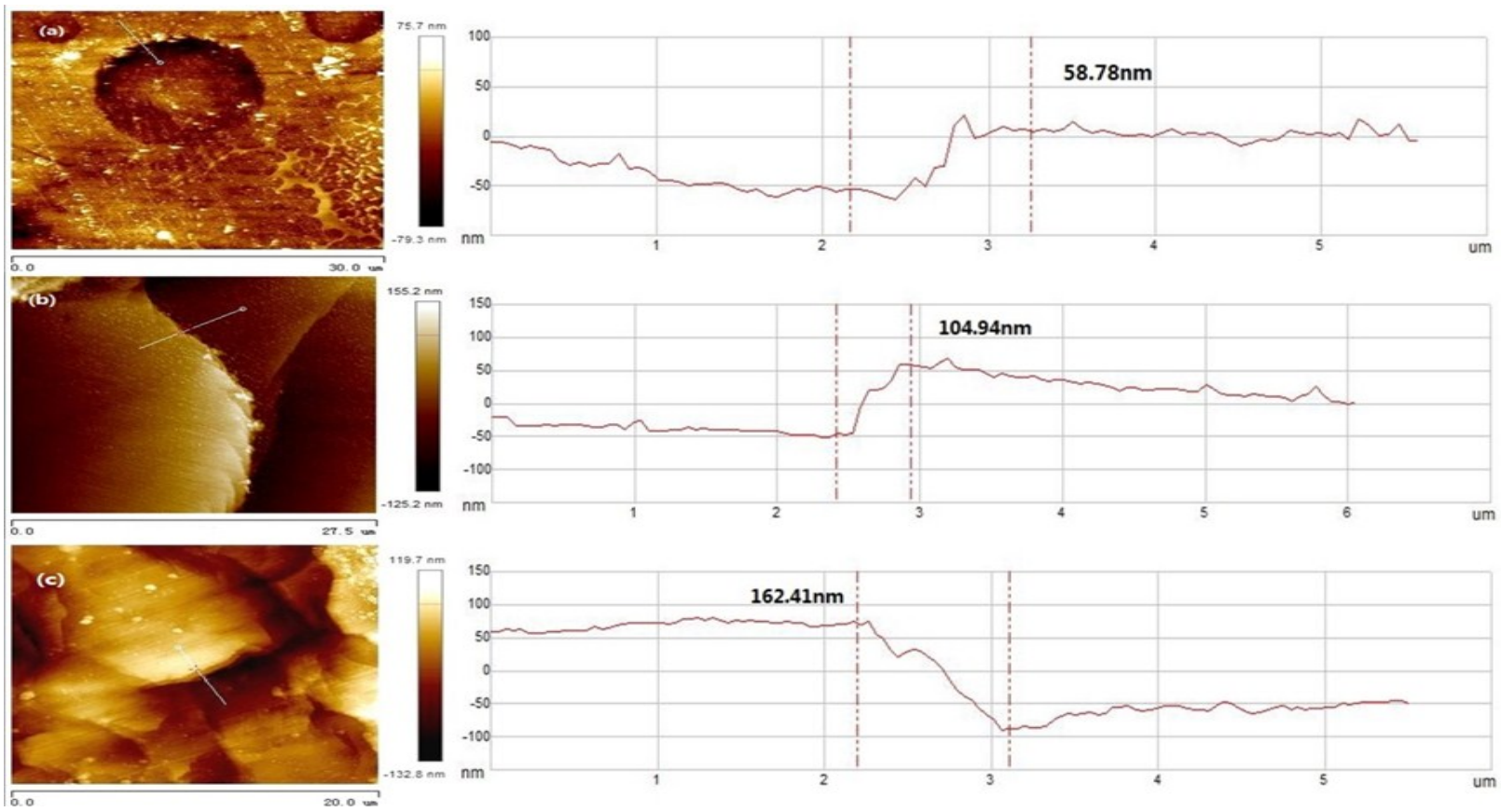

Fig. 4 AFM images of BMGs' impact area, (a) the height of the circle edge in La-based BMG, (b) the height of the arc edge in Zr-based BMG, (c) the height of the arc edge in the-based BMG

In addition, we investigate the relation between the edge height and BMGs with different toughness. $\mathrm{Xi}$ et al. believed that the concept of plastic deformation area can be used to represent the brittleness or ductility of BMGs [21]. Ductile BMGs have a larger plastic deformation zone, for example, to $\mathrm{Zr}_{41} \mathrm{Ti}_{14} \mathrm{Cu}_{12.5} \mathrm{Ni}_{10} \mathrm{Be}_{22.5}$ BMGs, the size of the plastic deformation area is $57.1 \mu \mathrm{m}$ [22]. While the size of localized structures in brittle BMGs is rather small, which is only $28 \mathrm{~nm}$ in $\mathrm{Fe}_{46} \mathrm{Ni}_{32} \mathrm{~V}_{2} \mathrm{Si}_{14} \mathrm{~B}_{6} \mathrm{BMGs}$ [23]. In our work, as shown in Fig. 4, the edge height of feature structures in La-based BMG, Zr-based BMG and Ti-based BMG is $67.26 \mathrm{~nm}, 104.94 \mathrm{~nm}$ and $162.41 \mathrm{~nm}$, respectively. The higher is the edge height in the feature structure, the better ductile property of BMG. The result shows that the edge height of feature structure change with the property of ductility in BMGs, which accords well with the results obtained by $\mathrm{Xi}$ et al.

Further, the surface morphology of Zr-based BMG with different crystallize degrees is also studied. Annealing was induced to obtain different crystallization fractions. The transformed crystalline fraction can be evaluated by measuring the residual area of the crystallization peak in the non-isothermal DSC curves obtained after annealing. Fig. 5 shows Zr-based BMGs' DSC curves with different annealing time, The crystallization fractions $x(t)$ in the BMG can be estimated as:

$$
\mathrm{x}(\mathrm{t})=\frac{\Delta H_{\text {cast }}-\Delta H_{t}}{\Delta H_{\text {cast }}}
$$

Where $\Delta H_{t}$ and $\Delta H_{\text {cast }}$ are the measured enthalpy release during the continuous heating with and without annealing treatment [24]. 


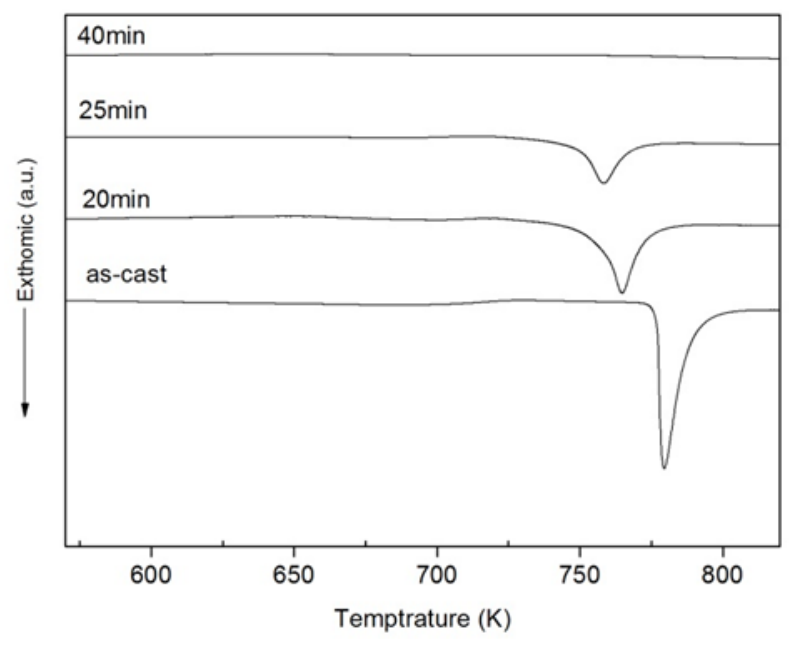

Fig. 5 DSC curves of Zr-based BMG with as-cast and different annealing time

Fig. 6 shows the SEM morphologies of different crystalline degrees after LSP with the same parameters. As shown in Fig. 6 (a), on the surface of $28 \%$ crystallized Zr-based BMG, the morphology of impacted area is more complex than as-cast BMGs. The number of circular- or arc-shaped is limited. There are many crisscross distribution structures, like steps, their length is up to several hundred microns. The phenomenon demonstrates that the degree of crystallization can influence the formation and pattern of feature structure on the surface of BMGs. By contrast with $28 \%$ crystallized sample, fewer circles and arcs can be found on the surface of the sample with a crystalline degree of $57 \%$ (as shown in Fig. 6 (b)). Different from partially crystalline samples, completely crystalline sample has no circular- or arc- shaped structure in the impact area (as shown in Fig. 6 (c)). The fact illuminates that the future structure of circular- or arc- shaped is unique in BMGs under the condition of LSP.

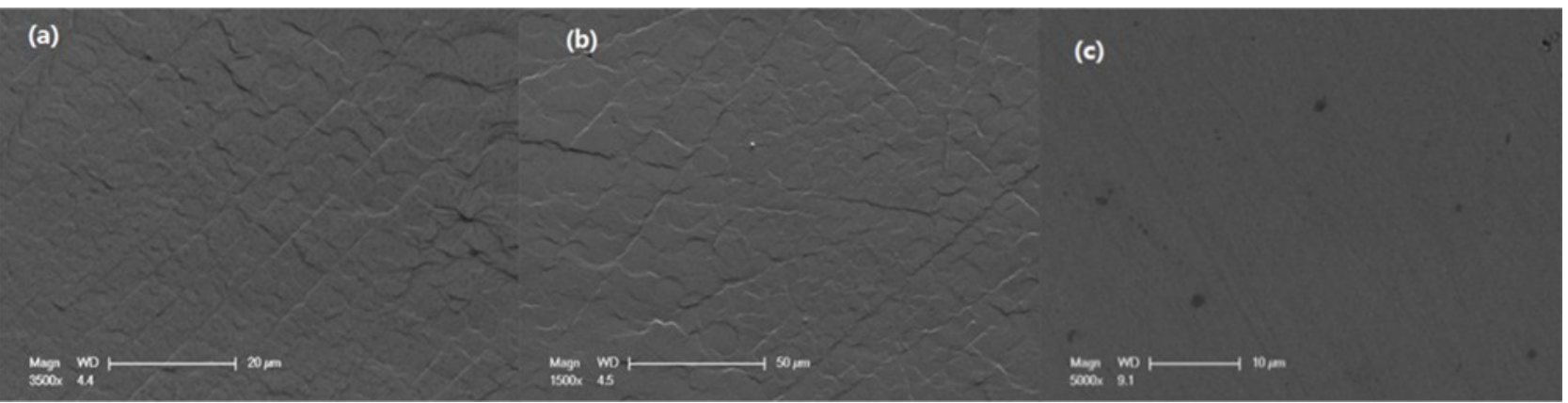

Fig. 6 SEM images of Zr-based BMG with different crystallization degree after LSP, (a) $28 \%$ crystallized, (b) $57 \%$ crystallized, (c) $100 \%$ crystallized

\section{Conclusion}

The appearance of arc- or circular- shaped structure is common in all BMGs upon laser shock peening. The scale of feature structure in different BMGs is diverse. For ductile BMG the morphology of impact area is more disordered and complicated, and the corresponding step height is higher, relative to other type BMGs. There is no any feature structure of circle and arc in completely crystalline BMGs after LSP. The result demonstrates that this kind of feature structure is unique in BMGs. With the increasing of crystallization degree, the feature structure is gradually reduced. 


\section{Acknowledgements}

The authors would like to acknowledge the support of the National Natural Science Foundation of China (Grant No.51271193, No.11332011, No.51401028). This work is also supported by the Strategic Priority Research Program of the Chinese Academy of Sciences (Grant No. XDB22040303).

\section{References}

[1] W. Klement, R.H. Willens, P. Duwez, Non-crystalline structure in solidified gold-silicon alloys, Nature. 187(1960) 869-870.

[2] W. H. Wang, C. Dong, C. H. Shek, Bulk metallic glasses, J. Materials Science and Engineering: R: Reports, 44(2004):45-89.

[3] D. Chen, A. Takeuchi, A. Inoue, Gd-Co-Al and Gd-Ni-Al bulk metallic glasses with high glass forming ability and good mechanical properties, J. Materials Science and Engineering: A, 457(2007): 226-230.

[4] X. Tong, G. Wang, Z. H. Stachurski, J. Bednarcik, N. Mattern, Q. J. Zhai, J. Eckert, Structural evolution and strength change of a metallic glass at different temperatures, J. Scientific Reports, 6(2016).

[5] B.Q. Chen, Y. Li, M. Yi, R. Li, S.J. Pang, H. Wang, T. Zhang, Optimization of mechanical properties of bulk metallic glasses by residual stress adjustment using laser surface melting, J. ScriptaMaterialia, 66(2012): 1057-1060.

[6] M. L. M. Sistiaga, R. Mertens, B. Vrancken, X. Wang, B. V. Hooreweder, J. P. Kruth, J.V. Humbeeck, Changing the alloy composition of A17075 for better processability by selective laser melting, J. Journal of Materials Processing Technology, 2016, 238(2016): 437-445.

[7] S. González, J. Fornell, E. Pellicer, S. Suriñach, M. D. Baró, A. L. Greer, F. J. Belzunce, J. Sort, Influence of the shot-peening intensity on the structure and near-surface mechanical properties of Ti40Zr10Cu38Pd12 bulk metallic glass, J. Applied Physics Letters, 103(2013): 211907.

[8] J. Fornell, A. Concustell, A. L. Greer, S. Suriñach, M. D. Baró, J.Sort, Effects of shot peening on the nanoindentation response of $\mathrm{Cu} 47.5 \mathrm{Zr} 47.5 \mathrm{Al} 5$ metallic glass, J. Journal of Alloys and Compounds, 586(2014): S36-S40.

[9] C. S. Montross, T. Wei, L. Ye, G. Clark, Y. W. Mai, Laser shock processing and its effects on microstructure and properties of metal alloys: a review, J. International Journal of Fatigue, 24(2002): 1021-1036.

[10]Y. Cao, X. Xie, J. Antonaglia, B. Winiarski, G. Wang, Y. C. Shin, P. J. Withers, K. A. Dahmen, P. K. Liaw, Laser shock peening on Zr-based bulk metallic glass and its effect on plasticity: experiment and modeling, J. Scientific reports, 5(2015): 10789.

[11]L. Wang, L. Wang, Z. H. Nie, Y. Ren, Y. F. Xue, R. H. Zhu, H.F. Zhang, H. M. Fu, Evolution of residual stress, free volume, and hardness in the laser shock peened Ti-based metallic glass, J. Materials \& Design, 111(2016): 473-481.

[12]Y. Zhang, W. H. Wang, A. L. Greer, Making metallic glasses plastic by control of residual stress, J. Nature materials, 5(2016): 857-860.

[13]C. H. Li, Q. Q. Duan, Z. F.Zhang, Tearing Toughness of Ductile Metals, J. Acta Metallurgica Sinica (English letters), 29(2016): 150-155.

[14]G. Li, M. Q. Jiang, F. Jiang, L. He, J. Sun, The ductile to brittle transition behavior in a Zr-based bulk metallic glass, J. Materials Science and Engineering: A, 625(2015): 393-402. 
[15]Y. H. Sun, Inverse ductile-brittle transition in metallic glasses, J. Materials Science and Technology, 31(2015): 635-650.

[16]D. C. Hofmann, J. Y. Suh, A. Wiest, G. Duan, M. L. Lind, M. D. Demetriou, W. L Johnson, Designing metallic glass matrix composites with high toughness and tensile ductility, J. Nature, 451(2008): 1085-1089.

[17]T. Lu, L. Xia, Z. Hu, et al. Deformation patterns in Zr-based and Ti-based metallic glasses under scratch processes, J. Scientia Sinica Physica, Mechanica \& Astronomica, 42(2012): 603.

[18]J. Eckert, J. Das, S. Pauly, C. Duhamel, Mechanical properties of bulk metallic glasses and composites, J. Journal of materials research, 22(2007): 285-301

[19]C. S. Montross, T. Wei, L. Ye, G. Clark, Y. W. Mai, Laser shock processing and its effects on microstructure and properties of metal alloys: a review, J. International Journal of Fatigue, 24(2002): 1021-1036.

[20]J.N. Johnson, R.W. Rhode, Dynamic deformation twinning in shock loaded iron, J. Journal of Applied Physics 42(1971):4171-82.

[21]X. K. Xi, D. Q. Zhao, M. X. Pan, W. H. Wang, Y. Wu, J. J. Lewandowski, Fracture of brittle metallic glasses: brittleness or plasticity, J. Physical review letters, 94(2005): 125510.

[22] R. D. Conner, A. J. Rosakis, W. L. Johnson, D. M. Owen, Fracture toughness determination for a beryllium-bearing bulk metallic glass, J. Scripta Materialia, 37(1997): 1373-1378.

[23]C. H. Shek, G. M. Lin, K. L. Lee, J. K. L. Lai, Fractal fracture of amorphous Fe46Ni32V2Si14B6 alloy, J. Journal of non-crystalline solids, 224(1998):244-248.

[24]Á. Révész, A. Concustell, L.K. Varga, S. Suriñach, M.D. Baró, Influence of the wheel speed on the thermal behaviour of Cu60Zr20Ti20 alloys, Mater. Sci. Eng. A. 375(2004) 776-780. 